\title{
Desmopressin versus Oxybutynin for Nocturnal Enuresis in Children in Bandar Abbas: A Randomized Clinical Trial
}

\author{
Kambiz Ghasemi ${ }^{1}$, Maryam Esteghamati ${ }^{1}$, Malihe Mohammadzadeh ${ }^{2}$, Shahram Zare ${ }^{3}$
}

${ }^{1}$ M.D., Assistant Professor, Department of Pediatric Nephrology, Faculty of Medicine, Hormozgan University of Medical Sciences, Bandar Abbas, Iran

${ }^{2}$ M.D., Pediatric Resident, Department of Pediatrics, Faculty of Medicine, Hormozgan University of Medical Sciences, Bandar Abbas, Iran

${ }^{3}$ Ph.D., Associate Professor, Department of Statistics, Faculty of Medicine, Hormozgan University of Medical Sciences, Hormozgan, Iran

Type of article: Original

\begin{abstract}
Background: Nocturnal enuresis is among the most common disorders in children. Several pharmacological and non-pharmacological treatments are available for nocturnal enuresis. Studies for reaching the best pharmacological treatment for this disorder are continuing.

Objective: To compare the effectiveness and safety of Desmopressin and oxybutynin for treatment of nocturnal enuresis in children from Bandar Abbas in 2014.

Methods: This randomized controlled trial was conducted in 2014 and participants included 66 children with nocturnal enuresis who were more than 5 years old. Patients were randomly assigned into two groups. The first group received 120 microgram Desmopressin daily for 2 months, then 60 microgram daily for 2 months, then 60 microgram every 2 days. The second group received $5 \mathrm{mg}$ oxybutynin twice a day for 6 months. The patients were followed after 1,3, and 6 months to track treatment response. The study outcomes were frequency of nocturnal enuresis, urinary incontinency, urgency, and frequency. Data were analyzed using SPSS software.

Results: There were no significant differences between the two groups with respects to sex, age, place of residence, and parents' education $(\mathrm{p}<0.05)$. Nocturnal enuresis, incontinency, urgency, and frequency of nocturnal enuresis was significantly lower with Desmopressin treatment in comparison to the oxybutynin treated group after 1 and 3 months $(\mathrm{p}<0.05)$. In addition, constipation and xerostomia were more frequent among the oxybutynin group after 1,3 , and 6 months $(\mathrm{p}<0.01)$. Blurred vision was also more frequent among oxybutynin group after 3 months $(\mathrm{p}<0.01)$. After 6 months the frequency of nocturnal enuresis and its frequency was higher in oxybutynin group in comparison to the Desmopressin group $(\mathrm{p}<0.05)$.

Conclusion: Desmopressin is more effective and has lower rate of side effects in comparison to oxybutynin for treatment of nocturnal enuresis. We recommend using Desmopressin for treatment of nocturnal enuresis in children. More studies are needed to achieve the best pharmacological treatment option for treatment of nocturnal enuresis.

Trial registration: The trial is registered at ClinicalTrials.gov with a ClinicalTrials.gov Identifier: NCT02538302

Funding: The funder of this research is Hormozgan University of Medical Sciences.

Keywords: Oxybutynin, Desmopressin, nocturnal enuresis
\end{abstract}

\section{Corresponding author:}

Dr. Malihe Mohammadzadeh, Department of Pediatrics, Faculty of Medicine, Hormozgan University of Medical Sciences. Tel: +98.9177314740, Email: Pahlavanzadeh@sksco.ir

Received: April 12, 2015, Accepted: September 04, 2015, Published: March 2016

iThenticate screening: September 09, 2015, English editing: November 01, 2015, Quality control: February 27, 2016 (C) 2016 The Authors. This is an open access article under the terms of the Creative Commons Attribution-NonCommercialNoDerivs License, which permits use and distribution in any medium, provided the original work is properly cited, the use is non-commercial and no modifications or adaptations are made. 


\section{Introduction}

\subsection{Background}

Nocturnal enuresis is a common disorder among children. Several pharmacological treatments are available for treatment of nocturnal enuresis (1-4). The available results for management of nocturnal enuresis are inconsistent. Several trials have shown the effectiveness of different pharmacological treatments in management of nocturnal enuresis, but side effects are common (5-8). Therefore, additional studies are needed to find the most effective medication with fewer side effects.

\subsection{Statement of problem}

Desmopressin is the first line treatment for management of nocturnal enuresis $(1,2)$. Unfortunately, its usage is limited due to the occurrence of hyponatremia and seizure, which are important side effects. Desmopressin is an analog of vasopressin that inhibits urination through reabsorption of water and solutes. Studies have shown its efficacy in children with nocturnal enuresis with polyuria (3). Oxybutynin is an anti-cholinergic agent that functions through relaxation of the detrusor muscle (4). Oxybutynin is the most common medication used for treatment of nocturnal enuresis in children. In addition, this drug has efficacy in treatment of urge incontinency, neurogenic bladder, daily incontinency, urgency, and in patients with restricted bladder capacity and thickened bladder wall (57). Common side effects include xerostomia, exophthalmia, and neurologic problems $(4,8)$.

\subsection{Objectives}

The general objectives of this study were to compare the effectiveness and safety of Desmopressin and oxybutynin for treatment of nocturnal enuresis in children. The specific objectives included:

1) To compare the effectiveness and safety of Desmopressin and oxybutynin in treatment of nocturnal enuresis in children 1 months after treatment

2) To compare the effectiveness and safety of Desmopressin and oxybutynin in treatment of nocturnal enuresis in children 3 months after treatment

3) To compare the effectiveness and safety of Desmopressin and oxybutynin in treatment of nocturnal enuresis in children 6 months after treatment

\section{Material and Methods}

\subsection{Study design and setting}

This randomized controlled trial was done in 2014 at Koodakan Hospital in Bandar Abbas, southern Iran. Koodakan Hospital is the only educational and referral hospital in the Hormozgan province.

\subsection{Study population, sampling and sample size}

Study population were $>5$ years old children with nocturnal enuresis attending Koodakan hospital in Bandar Abbas. A total of 66 nonconsecutive children were enrolled in the study after examination of their eligibility according to the inclusion and exclusion criteria.

\subsection{Inclusion criteria}

The inclusion criteria of the study included the followings:

1) $>5$ years old

2) Nocturnal enuresis

3) Candidate for pharmacological treatment

\subsection{Exclusion criteria}

Patients were excluded if they had one of the following criteria:

1) Parents did not complete the informed consent form

2) Inability of follow up during the study period

3) History of seizure

4) History of rheumatologic disorders, including Sjogren's disease

\subsection{Randomization}

Patients were randomly assigned into two groups using simple randomization. The assignment ratio was equal in both groups. 


\subsection{Intervention}

The first group received 120 micrograms Desmopressin daily for 2 months, then 60 microgram daily for 2 months, then 60 microgram every 2 days. The second group received $5 \mathrm{mg}$ oxybutynin twice a day for 6 months.

\subsection{Blinding}

This study was a double blinded clinical trial. The patients, their parents, and the outcome assessors were not aware of group assignments.

\subsection{Outcome}

Patients were evaluated for existence of nocturnal enuresis, its frequency per week, daily urinary incontinency, urgency, and frequency before treatment and after 1, 3, and 6 months of treatment. Patients were also evaluated for drug side effects, including xerostomia, exophthalmia, blurred vision, dysphagia, constipation, diarrhea, headache, seizure, nose bleeding, abdominal pain, ear ache, retinitis, chest pain, and increased appetite, after 1, 3, and 6 months from the start of treatment.

\subsection{Statistical analysis}

Data was analyzed using IBM SPSS version 21.0 software using descriptive statistics (including frequency, percentage, mean, and standard deviation). In addition, independent samples t-test and chi-square tests were used for data analysis.

\subsection{Ethical issues}

The study protocol was confirmed by ethics committee of Hormozgan University of Medical Sciences. A written informed consent was obtained from all parents of the children involved. Information regarding patients, and their laboratory and imaging test results were kept confidential.

\section{Results}

3.1. Demographic information and baseline characteristics

We enrolled 66 children in this study (Figure 1). Among them $51(77.3 \%)$ were male and $15(22.7 \%)$ were female. Furthermore, $57(86.4 \%)$ were living in urban areas and 9 (13.6\%) were living in rural areas. In this study 39 (59.1\%) were assigned Desmopressin treatment and 27 (40.9\%) were assigned oxybutynin treatment. The mean age of the participants was $7.06 \pm 0.99$ years, which was variable between 6 and 11 years. The baseline characteristics of patients in two groups are shown in Table 1. The two groups have similar baseline characteristics.

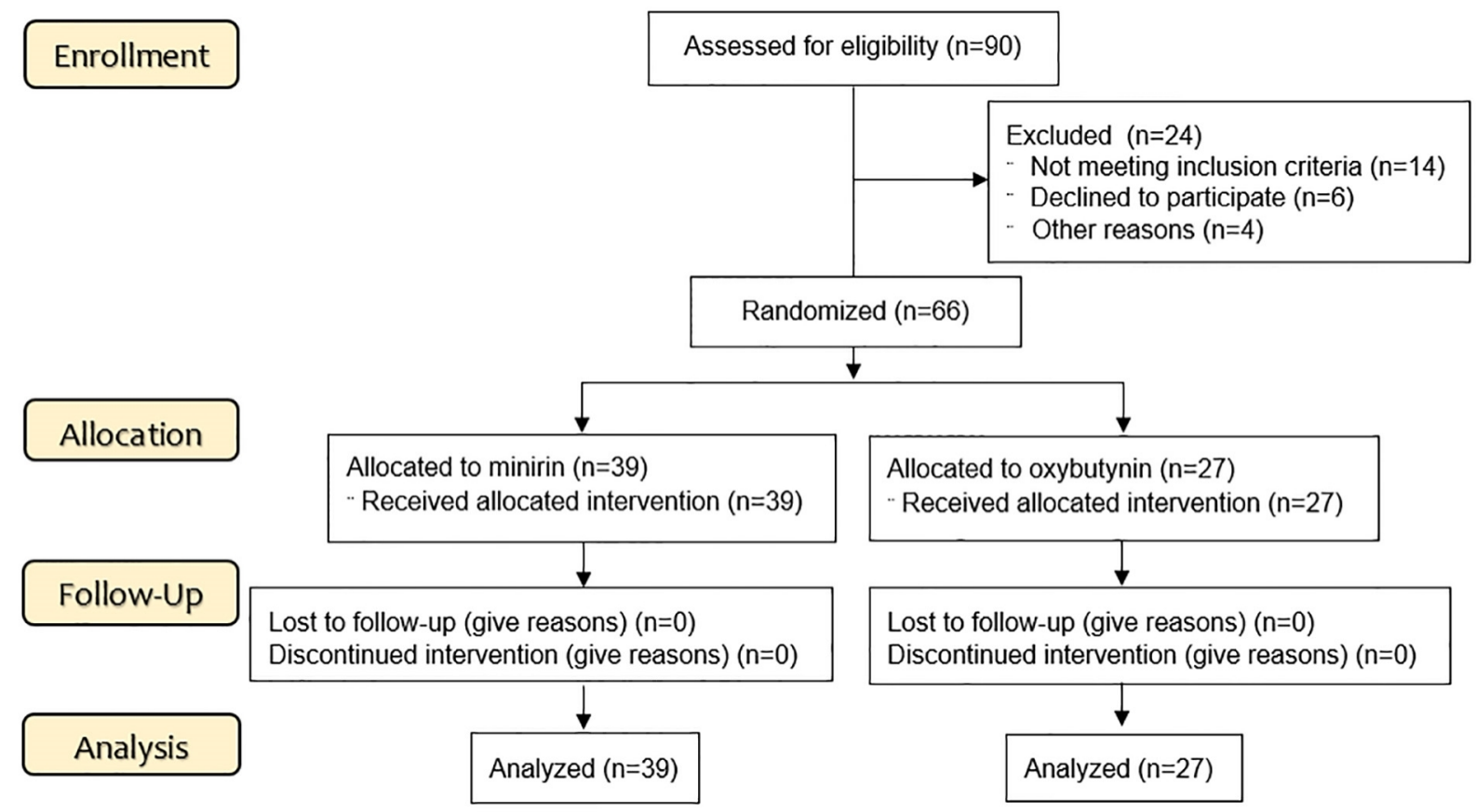

Figure 1. The flow chart of the study participants 
Table 1. Baseline characteristics of two groups

\begin{tabular}{|l|l|l|l|}
\hline Baseline characteristics & Desmopressin; n (\%) & Oxybutynin; n (\%) \\
\hline \multirow{2}{*}{ Gender } & Male & $30(76.9 \%)$ & $21(77.8 \%)$ \\
\cline { 2 - 4 } & Female & $9(23.1 \%)$ & $6(22.2 \%)$ \\
\hline \multirow{2}{*}{ Place of residence } & Urban areas & $34(87.2 \%)$ & $23(85.2 \%)$ \\
\cline { 2 - 4 } & Rural areas & $5(12.8 \%)$ & $4(14.8 \%)$ \\
\hline Age (year) & $6.92 \pm 0.83$ & $7.27 \pm 1.1$ \\
\hline Nocturnal enuresis & $39(100 \%)$ & $27(100 \%)$ \\
\hline Urinary incontinency & $2(5.1 \%)$ & $5(18.5 \%)$ \\
\hline Frequency of nocturnal enuresis (per week) & $18.28 \pm 5.47$ & $18.85 \pm 6.9$ \\
\hline Urgency & $1(2.6 \%)$ & $7(25.9 \%)$ \\
\hline Frequency & $38(97.4 \%)$ & $25(92.6 \%)$ \\
\hline
\end{tabular}

\subsection{Comparison of the study outcomes in two groups}

Our results showed that Desmopressin is more effective for management of nocturnal enuresis in children when compared to oxybutynin. Details are shown in Table 2. As shown in this table, patients in the Desmopressin group were asymptomatic 3 months after starting the treatment.

Table 2. Comparison of study outcomes in two groups

\begin{tabular}{|c|c|c|c|c|}
\hline \multicolumn{2}{|c|}{ Study outcome } & Desmopressin; n (\%) & Oxybutynin; n (\%) & $\mathrm{p}$ \\
\hline \multirow{5}{*}{$\begin{array}{l}\text { After } 1 \\
\text { month }\end{array}$} & Nocturnal enuresis & $25(64.1 \%)$ & $25(92.6 \%)$ & 0.008 \\
\hline & Urinary incontinency & $0(0 \%)$ & $5(18.5 \%)$ & 0.005 \\
\hline & Frequency of nocturnal enuresis (per week) & $3.10 \pm 2.67$ & $10.29 \pm 6.55$ & $<0.001$ \\
\hline & Urgency & $0(0 \%)$ & $5(18.5 \%)$ & 0.005 \\
\hline & Frequency & $0(0 \%)$ & $0(0 \%)$ & - \\
\hline \multirow{5}{*}{$\begin{array}{l}\text { After } 3 \\
\text { months }\end{array}$} & Nocturnal enuresis & $0(0 \%)$ & $17(63 \%)$ & $<0.001$ \\
\hline & Urinary incontinency & $0(0 \%)$ & $4(14.8 \%)$ & 0.013 \\
\hline & Frequency of nocturnal enuresis per week & - & $6.37 \pm 6.73$ & $<0.001$ \\
\hline & Urgency & $0(0 \%)$ & $1(3.7 \%)$ & 0.226 \\
\hline & Frequency & $0(0 \%)$ & $0(0 \%)$ & - \\
\hline \multirow{5}{*}{$\begin{array}{l}\text { After } 6 \\
\text { months }\end{array}$} & Nocturnal enuresis & $0(0 \%)$ & $13(48.1 \%)$ & $<0.001$ \\
\hline & Urinary incontinency & $0(0 \%)$ & $1(3.7 \%)$ & 0.226 \\
\hline & Frequency of nocturnal enuresis per week & - & $3.55 \pm 4.57$ & $<0.001$ \\
\hline & Urgency & $0(0 \%)$ & $0(0 \%)$ & - \\
\hline & Frequency & $0(0 \%)$ & $0(0 \%)$ & - \\
\hline
\end{tabular}

\subsection{Comparison of drug side effects in two groups}

Oxybutynin had more side effects in comparison to Desmopressin. Details are shown in Table 3 and demonstrate that xerostomia, xerophtalmia, and constipation are common side effects of oxybutynin. These side effects are less prevalent with Desmopressin treatment.

\section{Discussion}

Nocturnal enuresis is one of the most common disorders among children and is associated with psychological problems in the affected children. Available pharmacological treatments for nocturnal enuresis include imipramine, anti-cholinergic agents such as oxybutynin $(4,9,10)$, and vasopressin analogs. Still, some controversy exists for the pharmacological treatment of nocturnal enuresis. The prevalence of nocturnal enuresis was higher among male children in our study. Other researchers have also reported a higher prevalence of nocturnal enuresis among male children, which may be due to higher psychological stress in male children.

\subsection{Effectiveness of the treatments}

Our results showed that the effectiveness of Desmopressin is higher when compared to oxybutynin for treatment of nocturnal enuresis. We found that the prevalence of nocturnal enuresis is significantly lower with Desmopressin treatment in comparison to oxybutynin treatment after one month. After 3 and 6 months no children in the Desmopressin group had nocturnal enuresis. Other studies have shown its efficacy in children with nocturnal 
enuresis and polyuria (3). Our study shows the effectiveness of Desmopressin in treatment of nocturnal enuresis in children, but based on the other study results it seems that Desmopressin's efficacy may be even higher in children with polyuria.

Table 3. Comparison of side effects of Desmopressin and oxybutynin after 1, 3, and 6 months

\begin{tabular}{|c|c|c|c|c|}
\hline \multicolumn{2}{|l|}{ Side effects } & Desmopressin; n (\%) & Oxybutynin; n (\%) & $\mathrm{p}$ \\
\hline \multirow[t]{15}{*}{ After 1 month } & Xerostomia & $0(0 \%)$ & $19(70.4 \%)$ & $<0.001$ \\
\hline & Xerophthalmia & $0(0 \%)$ & $2(7.4 \%)$ & 0.164 \\
\hline & Blurred vision & $0(0 \%)$ & $0(0 \%)$ & - \\
\hline & Dysphagia & $0(0 \%)$ & $0(0 \%)$ & - \\
\hline & Constipation & $2(5.1 \%)$ & $6(22.2 \%)$ & 0.036 \\
\hline & Diarrhea & $0(0 \%)$ & $0(0 \%)$ & - \\
\hline & Headache & $0(0 \%)$ & $0(0 \%)$ & - \\
\hline & Seizure & $0(0 \%)$ & $0(0 \%)$ & - \\
\hline & Epistaxis & $0(0 \%)$ & $0(0 \%)$ & - \\
\hline & Abdominal pain & $0(0 \%)$ & $0(0 \%)$ & - \\
\hline & Vomiting & $0(0 \%)$ & $0(0 \%)$ & - \\
\hline & Ear ache & $0(0 \%)$ & $0(0 \%)$ & - \\
\hline & Rhinitis & $12(30.8 \%)$ & $5(18.5 \%)$ & 0.263 \\
\hline & Chest pain & $1(2.6 \%)$ & $1(3.7 \%)$ & 0.791 \\
\hline & Increase in appetite & $0(0 \%)$ & $0(0 \%)$ & - \\
\hline \multirow[t]{15}{*}{ After 3 months } & Xerostomia & $0(0 \%)$ & $13(48.1 \%)$ & 0.001 \\
\hline & Xerophthalmia & $0(0 \%)$ & $1(3.7 \%)$ & 0.409 \\
\hline & Blurred vision & $0(0 \%)$ & $3(11.1 \%)$ & 0.033 \\
\hline & Dysphagia & $0(0 \%)$ & $0(0 \%)$ & - \\
\hline & Constipation & $0(0 \%)$ & $9(33.3 \%)$ & $<0.001$ \\
\hline & Diarrhea & $0(0 \%)$ & $0(0 \%)$ & - \\
\hline & Headache & $0(0 \%)$ & $0(0 \%)$ & - \\
\hline & Seizure & $0(0 \%)$ & $0(0 \%)$ & - \\
\hline & Epistaxis & $0(0 \%)$ & $0(0 \%)$ & - \\
\hline & Abdominal pain & $0(0 \%)$ & $0(0 \%)$ & - \\
\hline & Vomiting & $0(0 \%)$ & $0(0 \%)$ & - \\
\hline & Ear ache & $0(0 \%)$ & $1(3.7 \%)$ & 0.409 \\
\hline & Rhinitis & $0(0 \%)$ & $1(3.7 \%)$ & 0.409 \\
\hline & Chest pain & $2(5.1 \%)$ & $2(7.4 \%)$ & 0.703 \\
\hline & Increase in appetite & $0(0 \%)$ & $0(0 \%)$ & - \\
\hline \multirow[t]{15}{*}{ After 6 months } & Xerostomia & $0(0 \%)$ & $3(11.1 \%)$ & 0.033 \\
\hline & Xerophthalmia & $0(0 \%)$ & $0(0 \%)$ & - \\
\hline & Blurred vision & $0(0 \%)$ & $1(3.7 \%)$ & 0.226 \\
\hline & Dysphagia & $0(0 \%)$ & $0(0 \%)$ & - \\
\hline & Constipation & $0(0 \%)$ & $8(29.6 \%)$ & $<0.001$ \\
\hline & Diarrhea & $0(0 \%)$ & $0(0 \%)$ & - \\
\hline & Headache & $0(0 \%)$ & $0(0 \%)$ & - \\
\hline & Seizure & $0(0 \%)$ & $0(0 \%)$ & - \\
\hline & Epistaxis & $0(0 \%)$ & $0(0 \%)$ & - \\
\hline & Abdominal pain & $0(0 \%)$ & $0(0 \%)$ & - \\
\hline & Vomiting & $0(0 \%)$ & $0(0 \%)$ & - \\
\hline & Ear ache & $0(0 \%)$ & $0(0 \%)$ & - \\
\hline & Rhinitis & $18(46.2 \%)$ & $12(44.4 \%)$ & 0.891 \\
\hline & Chest pain & $1(2.6 \%)$ & $1(3.7 \%)$ & 0.791 \\
\hline & Increase in appetite & $0(0 \%)$ & $0(0 \%)$ & - \\
\hline
\end{tabular}




\subsection{Side effects of the treatments}

Side effects including constipation, xerostomia, and blurred vision were higher with oxybutynin treatment in comparison to Desmopressin treatment. Other studies have shown that xerostomia, xerophthalmia, and neurologic problems are common with oxybutynin use (4). The rate of side effects from treatment was low in the Desmopressin group. Therefore, based on the results of our study and other similar studies, Desmopressin seems to be a safe option for treatment of nocturnal enuresis in children. In addition to pharmacological treatment for nocturnal enuresis, some behavioral treatments are needed for these patients $(11,12)$. We recommend using pharmacological treatments in combination with non-pharmacological treatments. Also, more studies are recommended to evaluate the effectiveness of combination of pharmacological and non-pharmacological treatments.

\section{Conclusions}

Based on the results of this study, Desmopressin is more effective than oxybutynin in treatment of nocturnal enuresis in children. In addition, Desmopressin has fewer side effects than oxybutynin during treatment of nocturnal enuresis. We recommend using Desmopressin for treatment of nocturnal enuresis. More studies are needed for assessment of long term side effects of Desmopressin and oxybutynin in treatment of nocturnal enuresis.

\section{Acknowledgments:}

The paper is derived from research completed for the thesis of Malihe Mohammadzadeh in fulfilment of the requirements for a doctorate in pediatrics. The authors wish to thank to clinical research development center of Koodakan hospital in Hormozgan University of Medical Sciences for their help and support.

\section{Trial registration:}

The trial is registered at ClinicalTrials.gov with a ClinicalTrials.gov Identifier: NCT02538302

\section{Funding:}

The funder of this research is Hormozgan University of Medical Sciences.

\section{Conflict of Interest:}

There is no conflict of interest to be declared.

\section{Authors' contributions:}

All authors contributed to this project and article equally. All authors read and approved the final manuscript.

\section{References}

1) Miller K, Klauber GT. Desmopressin acetate in children with severe primary nocturnal enuresis. Clin Ther. 1990; 12(4): 357-66. PMID: 2224950.

2) Marschall-Kehrel D, Harms TW, Enuresis Algorithm of Marschall Survey G. Structured desmopressin withdrawal improves response and treatment outcome for monosymptomatic enuretic children. J Urol. 2009; 182(4 Suppl): 2022-6. doi: 10.1016/j.juro.2009.03.068. PMID: 19695616.

3) Lose G, Lalos O, Freeman RM, van Kerrebroeck P, Nocturia Study Group. Efficacy of desmopressin (Minirin) in the treatment of nocturia: a double-blind placebo-controlled study in women. Am J Obstet Gynecol. 2003; 189(4): 1106-13. PMID: 14586363.

4) Friedman BC, Friedman B, Goldman RD. Oxybutynin for treatment of nocturnal enuresis in children. Can Fam Physician. 2011; 57(5): 559-61. PMID: 21642736, PMCID: 3093588.

5) Montaldo P, Tafuro L, Rea M, Narciso V, Iossa AC, Del Gado R. Desmopressin and oxybutynin in monosymptomatic nocturnal enuresis: a randomized, double-blind, placebo-controlled trial and an assessment of predictive factors. BJU Int. 2012; $110(8$ Pt B): E381-6. doi: 10.1111/j.1464410X.2011.10918.x. PMID: 22313792

6) Caione P, Arena F, Biraghi M, Cigna RM, Chendi D, Chiozza ML, et al. Nocturnal enuresis and daytime wetting: a multicentric trial with oxybutynin and desmopressin. Eur Urol. 1997; 31(4): 459-63. PMID: 9187908.

7) Persson-Junemann C, Seemann O, Kohrmann KU, Junemann KP, Alken P. Comparison of urodynamic findings and response to oxybutynin in nocturnal enuresis. Eur Urol. 1993; 24(1): 92-6. PMID: 8365449. 
8) Varan B, Saatci U, Ozen S, Bakkaloglu A, Besbas N. Efficacy of oxybutynin, pseudoephedrine and indomethacin in the treatment of primary nocturnal enuresis. Turk J Pediatr. 1996; 38(2): 155-9. doi: PMID: 8701478.

9) Lee T, Suh HJ, Lee HJ, Lee JE. Comparison of effects of treatment of primary nocturnal enuresis with oxybutynin plus desmopressin, desmopressin alone or imipramine alone: a randomized controlled clinical trial. J Urol. 2005; 174(3): 1084-7. PMID: 16094064.

10) Deshpande AV, Caldwell PH, Sureshkumar P. Drugs for nocturnal enuresis in children (other than desmopressin and tricyclics). Cochrane Database Syst Rev. 2012; 12: CD002238. doi: 10.1002/14651858.CD002238.pub2. PMID: 23235587.

11) Cho SY, Lee KS, Kim JH, Seo JT, Choo MS, Kim JC, et al. Effect of combined systematized behavioral modification education program with desmopressin in patients with nocturia: a prospective, multicenter, randomized, and parallel study. Int Neurourol J. 2014; 18(4): 213-20. doi: 10.5213/inj.2014.18.4.213. PMID: 25558419, PMCID: 4280441.

12) Ahmed AF, Amin MM, Ali MM, Shalaby EA. Efficacy of an enuresis alarm, desmopressin, and combination therapy in the treatment of saudi children with primary monosymptomatic nocturnal enuresis. Korean J Urol. 2013; 54(11): 783-90. doi: 10.4111/kju.2013.54.11.783. PMID: 24255762, PMCID: 3830973 . 